\title{
Palpable Masses Evaluator
}

National Cancer Institute

\section{Source}

National Cancer Institute. Palpable Masses Evaluator. NCI Thesaurus. Code C119908.

A person who determines the significance of a palpable masses assessment. 